\title{
The Bacterial Component Flagellin Induces Anti-Sepsis Protection Through TLR-5, IL-1RN and VCAN During Polymicrobial Sepsis in Mice
}

\author{
Jiang Zhu ${ }^{a}$ Guangjie Duan ${ }^{a}$ Lang Lang ${ }^{b}$ Yao Liuc Junmin Zhu ${ }^{d}$ Hu Wang ${ }^{a}$ \\ Yousheng Liu ${ }^{\mathrm{a}}$ \\ aInstitute of Pathology, Southwest Hospital, Third Military Medical University, ${ }^{b}$ Department of Urology, \\ Southwest Hospital, Third Military Medical University, 'Department of Pharmacy, Southwest Hospital, \\ Third Military Medical University, ${ }^{\mathrm{D} D e p a r t m e n t}$ of Microbiology, College of Basic Medical Sciences, \\ Third Military, Medical University, Chongqing, China
}

\section{Key Words}

Sepsis • Toll-like receptor-5 • VCAN ・ IL-1RN • Flagellin

\begin{abstract}
Background: The present study was designed to observe the effects of the bacterial component flagellin on anti-sepsis protection through TLR-5, VCAN and IL-1RN. Methods: A clinically relevant model of sepsis was induced by cecal ligation and puncture (CLP). An in vitro culture of endothelial cells was analyzed. Results: Flagellin induced anti-sepsis protection through inhibition of inflammation and induction of endothelial proliferation by down-regulating the expression of TLR 3, TLR 4, and IL-1RN and promoting the expression of VCAN in mice $24 \mathrm{~h}$ post-CLP. In vitro, flagellin promoted the proliferation of endothelial cells. These effects could be inhibited by transfection of endothelial cells with VCAN siRNA or IL-1RN over-expression constructs. VCAN expression decreased after transfection of the cells with an IL-1RN over-expression construct and increased after transfection of the cells with an IL-1RN siRNA construct. IL-1RN expression remained unchanged after transfection of the cells with VCAN over-expression or siRNA constructs. Conclusions: These data suggest that flagellin pretreatment promoted anti-sepsis protection through the TLR-5, IL-1RN and VCAN pathway. This pathway is necessary to mediate endothelial repair and thereby promote survival following sepsis challenge.
\end{abstract}

J. Zhu and G. Duan made equal contributions to this research.

Yousheng Liu

KARGER 125
Institute of Pathology, Southwest Hospital, Third Military Medical University, 29 Gaotanyan Street, Shapingba Area, Chongqing 400038 (China)

Tel. +86-23-68765460, Fax +86-23-65460268, E-Mail youshengliu88@126.com 


\begin{tabular}{|c|c|c|}
\hline \multirow{2}{*}{$\begin{array}{l}\text { Cellular Physiology } \\
\text { and Biochemistry }\end{array}$} & Cell Physiol Biochem 2015;36:446-456 & \\
\hline & $\begin{array}{l}\text { DOI: 10.1159/000430111 } \\
\text { Published online: May 11, } 2015\end{array}$ & $\begin{array}{l}\text { O } 2015 \mathrm{~S} \text {. Karger AG, Basel } \\
\text { www.karger.com/cpb }\end{array}$ \\
\hline
\end{tabular}

\section{Introduction}

Septic shock caused by acute bacterial infection is a major cause of mortality in intensive care units. Dysregulation of the innate immune system during sepsis leads to inflammatory signal amplification upon cellular recognition of bacterial products. Sepsis is characterized by abnormal leukocyte activation, severe endothelial injuries, and ultimately organ failure due to septic shock [1].

Immune-stimulatory microbial and viral products, collectively known as pathogenassociated molecular patterns (PAMPs), are recognized by the immune system through conserved microbial structures. Toll-like receptors (TLRs) are a family of leucine-rich repeat (LRR)-containing proteins that possess three domains - an extracellular domain to sense microbes, a transmembrane domain and an intracellular toll-IL-1 receptor (TIR) signaling domain. TLR engagement leads to the rapid activation of signaling pathways, such as MAPK, $\mathrm{NF}-\kappa \mathrm{B}$, and/or IFN responsive factors (IRFs), leading to the massive release of inflammatory mediators into the bloodstream and culminating in septic shock [2].

In a previous study (unpublished data), we used the RT ${ }^{2}$ Profiler ${ }^{\mathrm{TM}}$ PCR Array Human Epithelial to Mesenchymal Transition and observed that flagellin inhibited the expression of IL-1RN and promoted the expression of VCAN. IL-1 gene expression occurs after activation of pattern recognition receptors (PRRs). Both microbial products and endogenous dangerassociated molecules stimulate the production of IL-1. Although the production of the pro-inflammatory cytokine IL-1 results in the subsequent release of a large quantity of inflammatory cytokines, the expression of various adhesion molecules and the release of proteases and superoxide by leukocytes that are helpful in fighting infection, these factors can also cause injury to endothelial cells. IL-1 acts in an autocrine/paracrine manner through the type I IL-1 receptor. In contrast, IL-1RN acts as an inhibitor of the pro-inflammatory cytokine IL-1 receptor. Mono-therapy targeted at blocking IL-1 activity in auto-inflammatory syndromes resulted in a rapid and sustained reduction in disease severity [3-5]. Therefore, IL-1RN can be effective in treating common conditions. Interestingly, the mechanism behind the anti-sepsis protection of flagellin may be related to the down-regulation of IL-1RN.

The extracellular matrix also plays a central role in wound repair in endothelial cells. To date, only two structural components of the extracellular matrix (versican (VCAN) and its binding partner hyaluronan) have been shown to be indispensably required for the differentiation and persistence of tissue phenotypes [6, 7].VCAN is a chondroitin sulfate proteoglycan that was first identified in fibroblastic extracts [8]. The role of VCAN in cell adhesion, migration, and proliferation has been extensively studied $[9,10]$. However, excessive expression of versican may be closely associated with the various malignant phenotypes of cancers [11].

In the present study, we used real-time PCR and western blotting to confirm the expression of IL-1RN and VCAN after flagellin administration. Then, we addressed the question of whether flagellin induces protective effects against septic shock by influencing the expression of IL-1RN and VCAN. To this end, we obtained a flagellin that was recognized by mouse TLR5. The administration of flagellin in mice abrogated CLP-induced increases in inflammatory cell numbers, total protein concentrations, and TNF- $\alpha$ and IL-8 levels in bronchoalveolar lavage fluid (BALF) and promoted a drastic induction of endothelial proliferation. We also investigated mechanisms including the expression of toll-like receptors, IL-1RN and VCAN. Based on our results, we propose flagellin as a strategy for the therapeutic prevention of septic shock.

\section{Materials and Methods}

Experimental protocols

Six-week-old male Balb/c mice (weight range, 18-22 g) were obtained from the Laboratory Animal Center of the Third Military Medical University (Chongqing, PR China). All mice received humane care 


\section{Cellular Physiology Cell Physiol Biochem 2015;36:446-456 \\ \begin{tabular}{l|l} 
DOI: 10.1159/000430111 & (C) 2015 S. Karger AG, Basel
\end{tabular} \\ www.karger.com/cpb \\ Zhu et al.: Flagellin Induced Anti-Sepsis Protection}

according to the guidelines of the Local Institutes of Health guide for the care and use of laboratory animals. A total of 100 mice were randomly divided into the control, CLP, flagellin ( $5 \mathrm{mg} / \mathrm{kg}$ ) and CLP+flagellin (1, 2,5 or $10 \mathrm{mg} / \mathrm{kg}$ ) groups. CLP was performed as described below. Briefly, the mice were anesthetized with ketamine and xylazine ( $45 \mathrm{mg} / \mathrm{kg}$ and $8 \mathrm{mg} / \mathrm{kg}$, i.p. respectively), and a 1-cm midline abdominal incision was then made. The cecum was identified, ligated and punctured with a 21-gauge needle. A small amount of cecal content was extruded to ensure the patency of the injury, and the cecum was then returned to the abdominal cavity. Control mice were treated with cecal manipulations without ligation and puncture. In the flagellin group, the Balb/c mice were administered flagellin (5 mg/kg, i.p.) $4 \mathrm{~h}$ before the sham operation. In the CLP+flagellin group, the Balb/c mice were administered flagellin (5 mg/kg, i.p.) $4 \mathrm{~h}$ before CLP. Purified flagellin from Pseudomonas aeruginosa (FLA-PA; $52 \mathrm{kDa}$ ) was purchased from Invivogen (USA).

\section{Assessment of lung functions}

Bronchoalveolar lavage fluid (BALF) was obtained by washing the airways three times with a total of 3 $\mathrm{ml}$ of $\mathrm{Ca} 2+/ \mathrm{Mg} 2+$-free saline through a tracheal cannula. The BALF was pooled and centrifuged at $4{ }^{\circ} \mathrm{C}, 1500$ $\mathrm{x} \mathrm{g}$, for $10 \mathrm{~min}$. The supernatant was harvested for total protein analysis using the BCA method, and the pellet was smeared onto slides for cell classification and counting with a modified Giemsa stain. The levels of TNF- $\alpha$ and IL- 8 in the bronchoalveolar lavage fluid were determined by ELISA performed according to the manufacturer's instructions (R\&D Systems, Minneapolis, MN, USA).

\section{Immunohistochemistry}

Following PBS perfusion, the lung tissues were fixed for 5 min by instillation of $10 \%$ PBS-buffered formalin through the trachea at a trans-pulmonary pressure of $15 \mathrm{~cm} \mathrm{H} \mathrm{H}_{2} \mathrm{O}$. After tracheal ligation, the lungs were fixed with $10 \%$ PBS-buffered formalin overnight at $4^{\circ} \mathrm{C}$. After the paraffin embedding process, the tissues were sectioned in 5- $\mu$ m-thick sections and the lung vascular endothelial cells were immunostained with anti-vWF (1:300, Sigma-Aldrich, St. Louis, MO, USA) and anti-CD31 (1:40, Abcam, Cambridge, MA, USA) antibodies at $4^{\circ} \mathrm{C}$. Then, the sections were incubated with biotinylated goat anti-mouse IgG for $1 \mathrm{~h}$. The signal was detected with 3,3'-diaminobenzidine. Omission of primary or secondary antisera was included as a control for each biopsy.

Analysis of toll-like receptors, IL-1RN and VCAN expression by real-time PCR

RNA was isolated from the lung tissues of Balb/c mice, reverse transcribed into cDNA and analyzed by quantitative real-time PCR with SYBR Green I (Invitrogen, China). The primers were designed using Primer 5.0 software and synthesized by Invitrogen (China) as follows:

TLR2-mouse (219 bp) Forward 5'-ctcccacttcaggctctttg - 3'

Reverse 5' - tcaggaactgggtggagaac - 3'

TLR3-mouse (219 bp) Forward 5'-tcggattcttggtttcaagg-3'

Reverse 5'-tttcggcttcttttgatgct-3'

TLR4-mouse (174 bp) Forward 5' - gctttcacctctgccttcac-3

Reverse 5'- gaaactgccatgtttgagca-3'

TLR5-mouse (193 bp) Forward 5'-gccacatcatttccactcct- 3'

Reverse 5' -acagccgaagttccaagaga- 3

IL-1RN-mouse (243 bp) Forward 5'-tggcctaggtgtcttctgct - 3'

Reverse 5' - atatgtgatgccctggtggt- 3'

VCAN-mouse (156 bp) Forward 5'-tccccaggaaacctatgatg- 3'

Reverse 5'-gctgcctgaagttctccaac- 3'

$\beta$-Actin -mouse (227 bp) Forward 5'-agccatgtacgtagccatcc - 3'

Reverse 5' - tctcagctgtggtggtgaag - 3'

Briefly, $2 \mu \mathrm{l}$ (out of $20 \mu \mathrm{l}$ ) of the reverse-transcribed reaction mixture was added to a $50 \mu \mathrm{l}$ PCR mixture for 35 cycles. Each cycle included $94^{\circ} \mathrm{C}$ for 20 seconds, $57^{\circ} \mathrm{C}$ for 30 seconds and $72^{\circ} \mathrm{C}$ for 30 seconds. The raw data were normalized to $\beta$-actin.

Analysis of IL-1RN and VCAN expression by western blotting

Lung tissues of Balb/c mice or various treatments of cells (as described in 2.7) were lysed in protease inhibitor cocktail solution (Roche, Indianapolis, IN, USA) for $1 \mathrm{~h}$ at $4^{\circ} \mathrm{C}$ and then centrifuged at $10,000 \mathrm{rpm}$ 


\section{Cellular Physiology Cell Physiol Biochem 2015;36:446-456 \\ \begin{tabular}{l|l} 
DOI: 10.1159/000430111 & (C) 2015 S. Karger AG, Basel
\end{tabular} \\ \begin{tabular}{l|l|} 
and Biochemistry Published online: May 11, 2015 & www.karger.com/cpb \\
\cline { 1 - 2 } & Zhus al.
\end{tabular} \\ Zhu et al.: Flagellin Induced Anti-Sepsis Protection}

for $1 \mathrm{~h}$ at $4^{\circ} \mathrm{C}$. Cell lysates ( $80 \mu \mathrm{g}$ ) were separated on 10\% SDS-PAGE after concentration assessment using a BCA kit (Dingguo, Beijing) and then transferred onto polyvinylidene fluoride membranes (Millipore, Billerica, MA, USA). The membranes were blocked with $5 \%$ skim milk and incubated with rabbit antimouse IL-1RN and VCAN antibodies (Cell Signaling Technology Inc.) at $4^{\circ} \mathrm{C}$ overnight. After washing, the membranes were incubated with horseradish peroxidase (HRP)-conjugated goat anti-rabbit IgG (1:5,000; Proteintech Group Inc., Chicago, IL, USA) for $1 \mathrm{~h}$ at room temperature. Antibody-antigen complexes were detected using an ECL chemiluminescent detection system (Gene Co., Ltd. Hong Kong, China). $\beta$-Actin was used as a loading control.

\section{Construction of recombinant vectors}

To generate the IL-1RN over-expression vector, the full-length cDNA of IL-1RN was obtained by double digestion with Xho I and BamH I (FastDigest, MBI Fermentas, Canada) from the recombinant plasmid pEGFP-C1/IL-1RN (previously constructed in our lab) and cloned into the Xho I/ BamH I sites of the pcDNA3.1(-)-myc-his vector with T4 DNA Ligase (FastDigest, MBI Fermentas). To generate the VCAN over-expression vector, the full-length cDNA of VCAN was amplified and inserted into the EcoRI/BamH I sites of pcDNA 3.1(-)-myc-his.

To generate the siRNA expression construct, three siRNA sequences (GenScript, China) for each gene were cloned into the pGCU6/Neo/RFP vector. One of the most effectively silenced plasmids (siRNA sequence for IL-1RN: AGAAGACAAGCGCUUUACCU; siRNA sequence for VCAN: UUCCUCUGCUGACAGAACCAC ) was chosen for the following studies. SVEC4-10EE2 murine endothelial cells (American Type Culture Collection, Manassas, VA, USA) were grown in 6-well plates at a density of $5 \times 10^{5}$ cells per well in DMEM medium containing $10 \% \mathrm{FBS}$ and $100 \mathrm{U} / \mathrm{ml}$ penicillin and streptomycin at $37^{\circ} \mathrm{C}$ with $5 \% \mathrm{CO} 2$. Recombinant plasmid DNA $(4 \mu \mathrm{g})$ and $8 \mu \mathrm{l}$ of the X-treme GENE HP DNA Transfection Reagent (Roche, USA) were mixed with 200 $\mu \mathrm{l}$ of medium without antibiotics and FBS and incubated at room temperature for $10 \mathrm{~min}$. Then, this mixture was added to the cells without removing the growth medium. The pcDNA3.1 (-)-myc-his and pGCU6/Neo/ RFP vectors were used as the vector controls.

After 24h, the transfected cells were selected using G418 (Ceresco, USA) at a concentration of $1000 \mathrm{mg}$ $\mathrm{ml}^{-1}$ and persistently cultured with G418 at a concentration of $200 \mathrm{mg} \mathrm{ml}^{-1}$.

Measurement of the cell cycle by flow cytometry

The control group cells were pre-treated with normal DMEM medium for $24 \mathrm{~h}$ then treated with $2 \mathrm{ml}$ of normal serum from mice for another $48 \mathrm{~h}$. The CLP group cells were pre-treated with DMEM medium for $24 \mathrm{~h}$ and then treated with $2 \mathrm{ml}$ of septic serum for another $48 \mathrm{~h}$. The CLP+flagellin group cells were pre-treated with flagellin $(50 \mathrm{ng} / \mathrm{mL})$ for $24 \mathrm{~h}$ and then treated with $2 \mathrm{ml}$ of septic serum for another $48 \mathrm{~h}$. The flagellin group cells were pre-treated with flagellin $(50 \mathrm{ng} / \mathrm{mL})$ for $24 \mathrm{~h}$ and then treated with $2 \mathrm{ml}$ of normal serum for another $48 \mathrm{~h}$. After the treatments, the cells were fixed in cold $70 \%$ ethanol and stored at $-20^{\circ} \mathrm{C}$ overnight. The fixed cells were washed twice with PBS, stained in a propidium iodide solution (50 ug/ $\mathrm{ml}$ ) for $1 \mathrm{~h}$, and treated with a ribonuclease A solution (20 ug/ml) for $30 \mathrm{~min}$. The cell cycle was examined using flow cytometry.

\section{Statistical analysis}

Analysis of data was performed using the unpaired t-test. The data are presented as the means \pm SD. Analysis was performed using SPSS 16.0 , and $p<0.05$ was considered to indicate a statistically significant difference.

\section{Results}

Effects of flagellin on lethality in CLP-induced mice

All mice in the normal control group survived. In the CLP-challenge group, the mice died at 6-10 h, and the lethality reached $100 \%$ at $48 \mathrm{~h}$. Pretreatment of the mice with flagellin (1, 2,5 or $10 \mathrm{mg} / \mathrm{kg}$ flagellin, i.p.) $4 \mathrm{~h}$ before CLP challenge significantly decreased the lethality in a concentration-dependent manner (Fig. 1). Because the highest doses of flagellin (5 and $10 \mathrm{mg} / \mathrm{kg}$ ) had the maximal effects, we selected the $5 \mathrm{mg} / \mathrm{mL}$ concentration for the subsequent experiments.

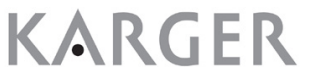


Fig. 1. Effects of various doses of flagellin on lethal toxicity in CLP-induced mice $(n=14)$. Balb/c mice were administered i.p. flagellin (1, 2.5 or $10 \mathrm{mg} / \mathrm{kg}) 4 \mathrm{~h}$ before CLP challenge. Lethality was evaluated within $48 \mathrm{~h}$ after CLP challenge. Pretreatment with flagellin significantly decreased the lethality in a concentration-dependent manner. ${ }^{*} p<0.05$ vs. CLP group.

Fig. 2. Effects of flagellin on lung functions in CLP-induced mice $(n=6)$. Balb/c mice were administered i.p. flagellin ( $5 \mathrm{mg} / \mathrm{kg}) 4 \mathrm{~h}$ before CLP challenge. The inflammatory cell numbers (A), total protein concentrations (B), TNF- $\alpha$ levels (C) and IL-8 levels (D) in BALF were increased at $24 \mathrm{~h}$ post-CLP challenge in a manner that was inhibited by flagellin. Immunohistochemistry of endothelial cells (E) expressing either CD31 in large vessels or vWF in capillaries revealed that flagellin induced a marked increase in endothelial cell numbers at $24 \mathrm{~h}$ post-CLP challenge, whereas the number of endothelial cells was minimal at the same time point in CLP-challenged lungs. Flagellin alone also induced a marked increase in endothelial cells of the control animals. Moreover, flagellin markedly reduced the infiltration of inflammatory cells into the intra-alveolar and interstitial space of lungs induced by CLP challenge ${ }^{* *} p<0.01$ vs. control; \#\# $p<0.01$ vs. CLP group.
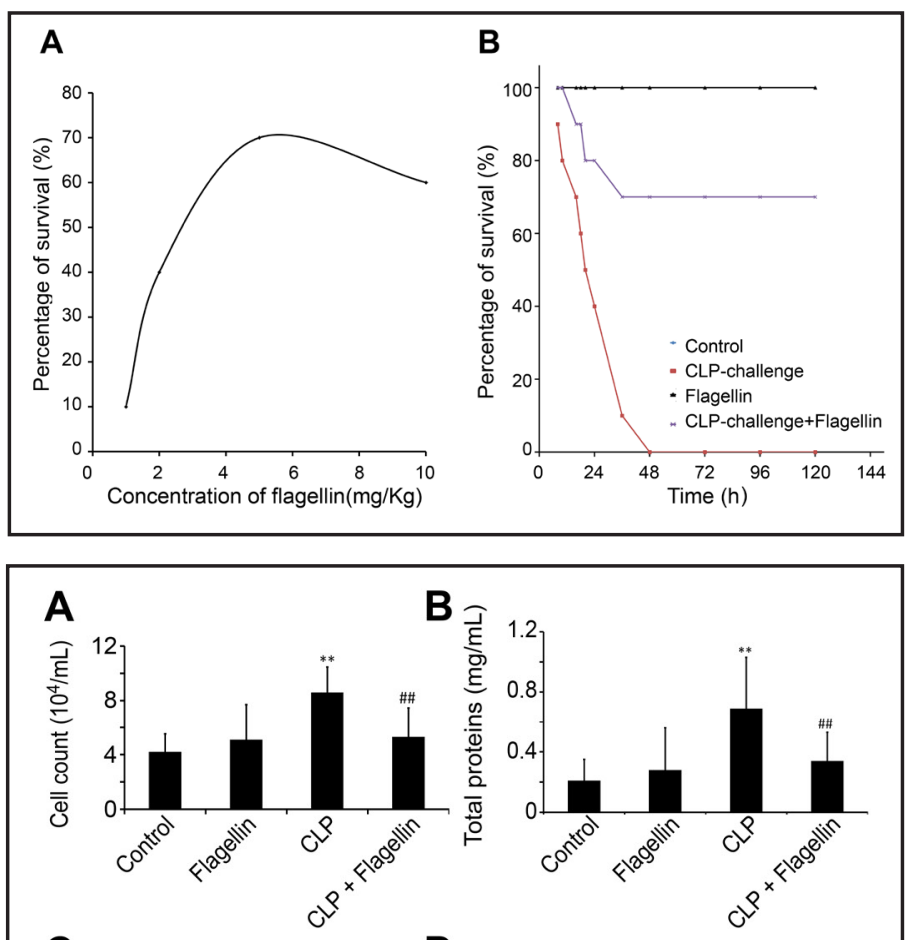

C

D

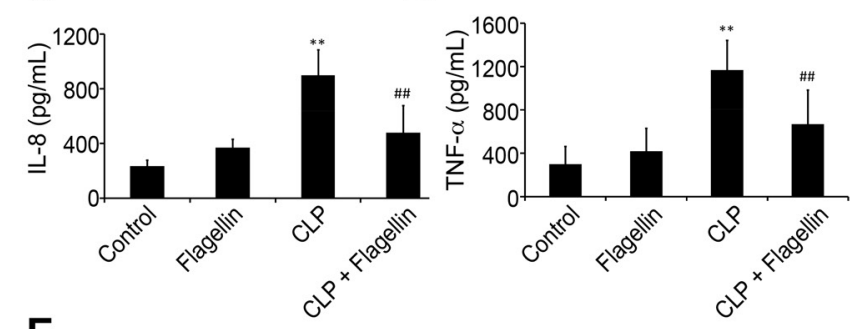

E

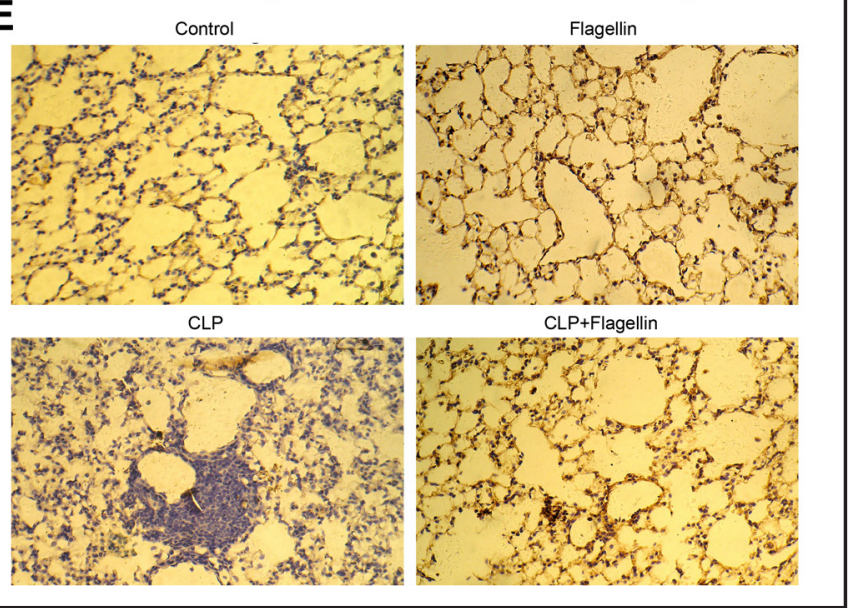

Effects of flagellin on lung functions in CLP-induced mice

The recruitment of inflammatory cells into the bronchoalveoli is known to represent a direct index of lung inflammatory responses. As expected, the inflammatory cell numbers, total proteins concentrations, and TNF- $\alpha$ and IL-8 levels in BALF were increased at $24 \mathrm{~h}$ post-CLP challenge, whereas treatment with flagellin $(5 \mathrm{mg} / \mathrm{kg}$, i.p., administered $4 \mathrm{~h}$ before CLP challenge) significantly inhibited these responses (Fig. 2A-D). Immunohistochemistry of endothelial cells (assessed by the expression of CD31 in the large vessels or vWF in the capillaries) revealed that flagellin induced a marked increase in the cell number $24 \mathrm{~h}$ post-CLP 


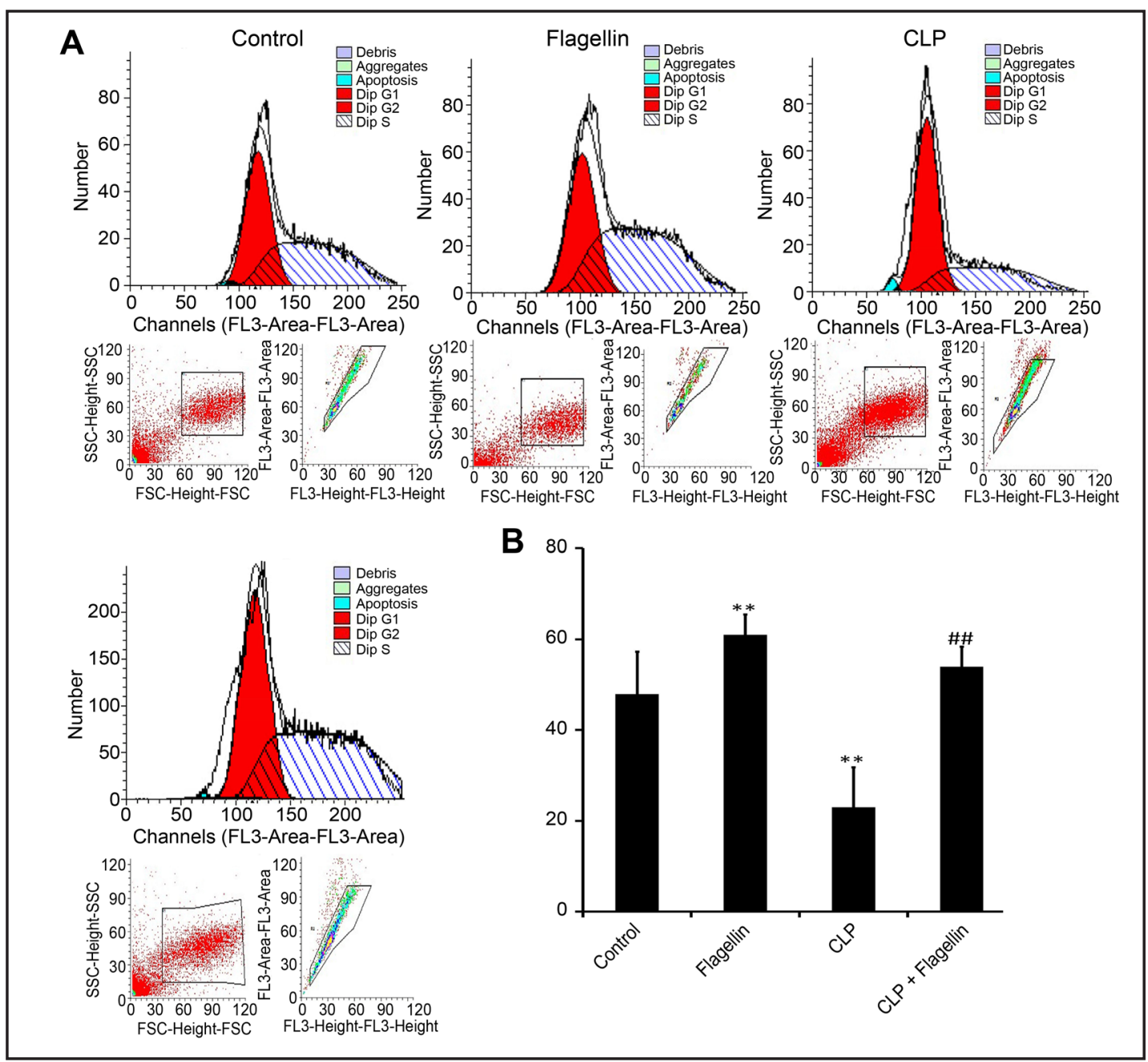

Fig. 3. The proliferation of SVEC4-10EE2 murine endothelial cells was assessed by flow cytometry $(n=3)$. Flagellin significantly promoted the proliferation of endothelial cells in the control and CLP groups. ** $p<0.01$ vs. control; \#\# $p<0.01$ vs. CLP challenge group.

challenge, whereas the change in the number of endothelial cells was minimal over the same time period in the lungs from CLP-challenged mice. Flagellin alone also induced a marked increase in endothelial cell numbers in the control animals. Moreover, the administration of flagellin markedly reduced the infiltration of inflammatory cells into the intra-alveolar and interstitial spaces of the lungs induced by CLP challenge (Fig. 2E).

Using flow cytometry, we observed that the number of endothelial cells in S-phase was significantly decreased in cultured endothelial cells. In contrast, the administration of flagellin significantly increased the numbers of cells in S-phase in the CLP and control group mice (Fig. 3).

\section{Effect of flagellin on TLR expression}

The flagellin used in our study was recognized by TLR5, and its interaction with TLR5 may influence the expression of other TLRs. Indeed, flagellin treatment stimulated TLR5 expression in normal mice (Fig. 4D). The expression of TLR-3, TLR-4 and TLR-5 were substantially increased in the CLP-challenged mice. However, treatment with flagellin decreased the mRNA levels of TLR-3 and TLR-4 in these mice (Fig. 4 A-D). 
Fig. 4. Effects of flagellin on toll-like receptor expression $(n=6)$. Balb/c mice were administered i.p. flagellin (5 mg/kg) $4 \mathrm{~h}$ before CLP challenge. The expression of TLR-2 (A) remained unchanged, while the expression of TLR-3 (B), TLR-4 (C) and TLR-5 (D) in lung tissues was increased at $24 \mathrm{~h}$ post-CLP challenge. Flagellin significantly inhibited the increases in TLR-3 and TLR-4. ${ }^{* *} p<0.01,{ }^{*} p<0.05$ vs. control; \#\# $p$ $<0.01$ vs. CLP group.

Fig. 5. Effects of flagellin on VCAN and IL-1RN expression in lung tissues $(n=6)$. Balb/c mice were administered i.p. flagellin (5 mg/kg) $4 \mathrm{~h}$ before CLP challenge. Real-time PCR (A) and western blotting (B) analysis showed that CLP challenge induced the expression of IL-1RN and inhibited the expression of VCAN in lungs $24 \mathrm{~h}$ post-CLP challenge. Flagellin inhibited the expression of IL$1 \mathrm{RN}$ and induced the expression of VCAN in lungs of mice $24 \mathrm{~h}$ post-CLP challenge. ${ }^{* *} p<0.01$ vs. control; \#\# $p$ $<0.01$ vs. CLP group.
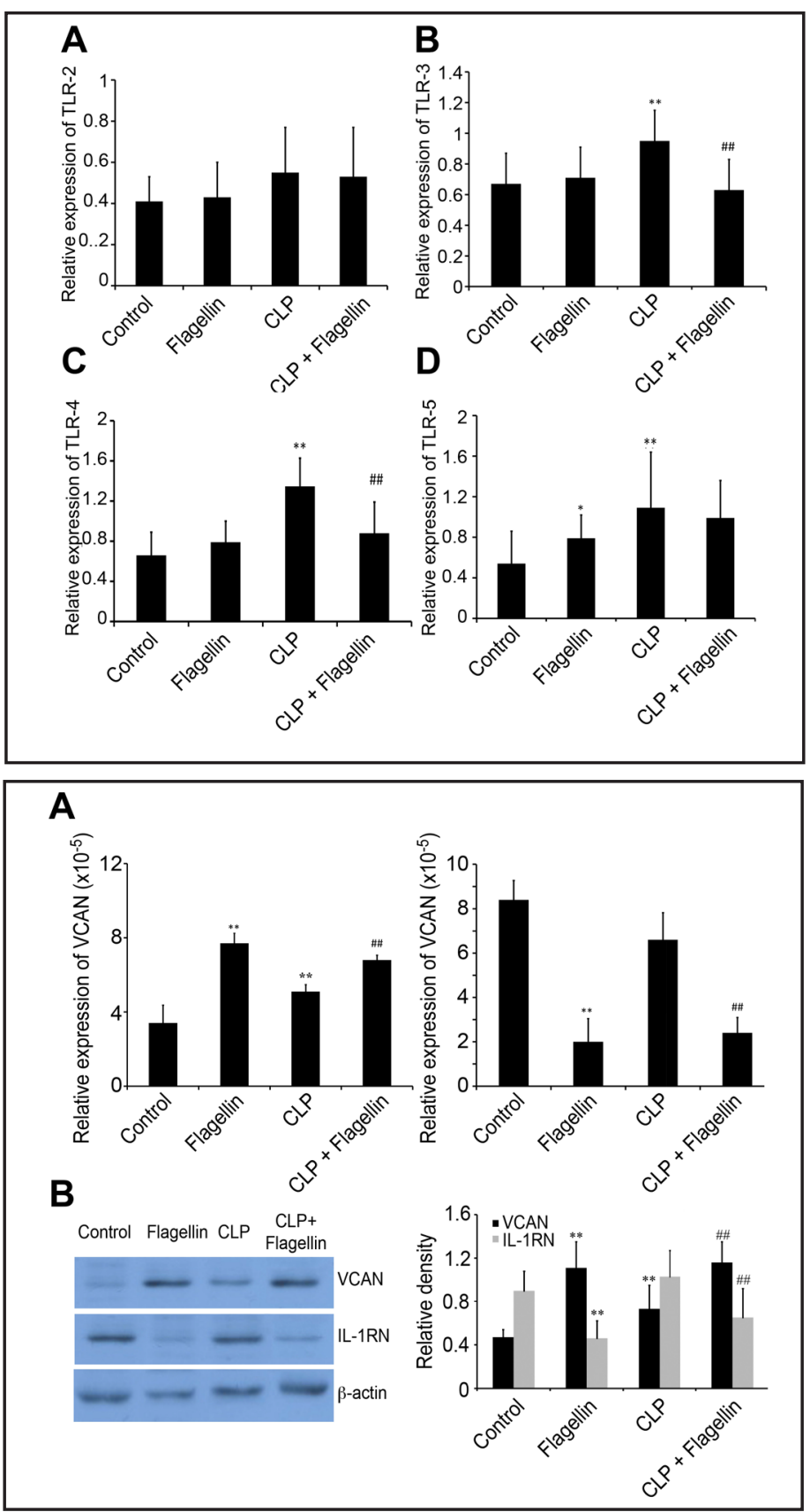

Effect of flagellin on VCAN and IL-1RN expression

To investigate the molecular basis of flagellin-induced anti-sepsis protection, we examined the expression of VCAN and IL-1RN. The results of real-time PCR and western blotting analysis (Fig. 5) showed that the expression of VCAN was decreased and IL-1RN was increased in the lungs of mice from the CLP challenge group. In contrast, the administration of flagellin in the GLP and control groups inhibited the expression of IL-1RN and induced the expression of VCAN (Fig. 5).

Flagellin promoted the proliferation of endothelial cells through the TLR-5/IL-1RN/VCAN pathway

To investigate the effects of VCAN and IL-1RN on the action of flagellin, we generated IL-1RN and VCAN over-expression constructs and siRNA expression constructs. Using 
Fig. 6. The expression of IL-1RN and VACN was assessed by western blotting. The expression of VCAN decreased after transfection of the cells with an IL-1RN over-expression construct, while VCAN expression increased after transfection of the cells with an IL-1RN siRNA construct. The expression of IL-1RN remained unchanged after transfection of the cells with a VCAN over-expression or siRNA construct when compared with the corresponding control vectors. ${ }^{* *} p<0.01$ vs. pcDNA 3.1; \#\# $p<0.01$ vs. pGUC6.

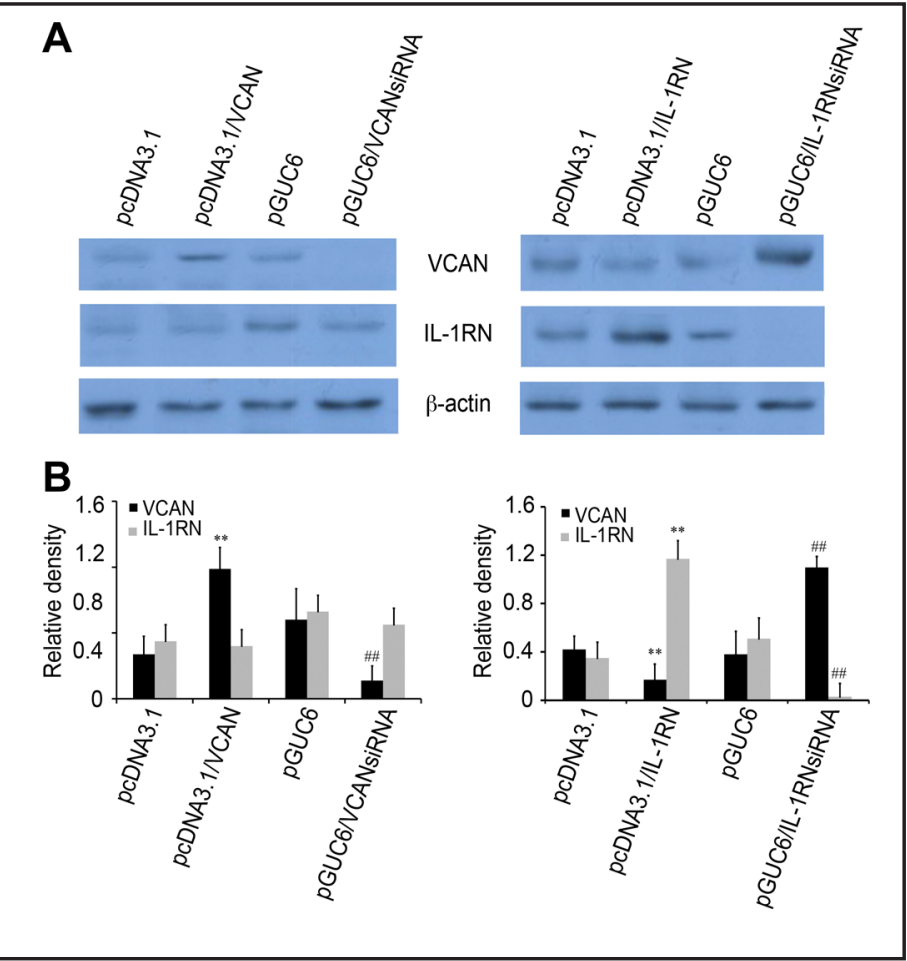

Fig. 7. The proliferation of SVEC410EE2 murine endothelial cells was assessed by flow cytometry $(n=3)$. The results showed that the VCAN siRNA construct inhibited the proliferation of endothelial cells. Flagellin significantly promoted the proliferation of endothelial cells in the control group. The promoting effects were inhibited by the transfection of endothelial cells with the IL1RN over-expression or VCAN siRNA constructs. ${ }^{* *} p<0.01$ vs. pcDNA3.1 or pGCU6; \#\# $p<0.01$ vs. Flagellin+ pcDNA3.1 or Flagellin+ pGCU6; $\$$ $p<0.01$ vs. pGCU6.

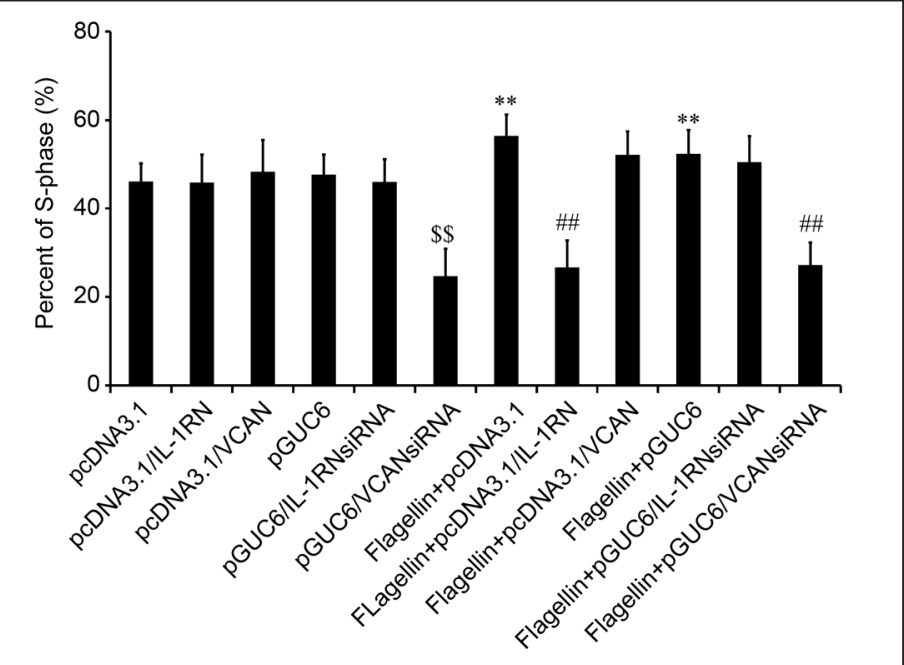

western blotting, we observed that the expression of VCAN decreased after transfection of the cells with the IL-1RN over-expression construct, while VCAN expression increased after transfection of the cells with the IL-1RN siRNA construct. In contrast, the expression of IL1RN remained unchanged after transfection of the cells with the VCAN over-expression or siRNA constructs compared with the corresponding control vectors (Fig. 6).

Using flow cytometry, we observed that the number of S-phase cells was significantly decreased in endothelial cells transfected with the VCAN siRNA construct compared with the corresponding control vector $(p<0.01)$ (Fig. 7). In contrast, the IL-1RN over-expression construct and the VCAN siRNA construct inhibited the flagellin-induced proliferation of endothelial cells (Fig. 7). 


\section{Cellular Physiology Cell Physiol Biochem 2015;36:446-456 \begin{tabular}{ll|l} 
and Biol 10.1159/000430111 & $\begin{array}{l}\text { O 2015 S. Karger AG, Basel } \\
\text { www.karger.com/cpb }\end{array}$ \\
\hline
\end{tabular} \\ Zhu et al.: Flagellin Induced Anti-Sepsis Protection}

\section{Discussion}

The results of our study show for the first time that pretreatment with flagellin inhibited the expression of toll-like receptors induced by polymicrobial infections, although the cell machinery involved in TLR signaling remains to be identified. TLRs are PPRs that help to maintain homeostasis by recognizing ligands known as microbial-associated molecular patterns (MAMPs) from both pathogenic and non-pathogenic bacteria [12]. They play roles in the development of both adaptive and innate immunity and subsequently create signals that promote the clearance of bacterial infections and the development of adaptive immunity [13]. In turn, they help maintain a healthy epithelial barrier. Thus, TLRs are key components involved in the innate defense against pathogens. Lipoteichoic acid (LTA), an integral part of the $\mathrm{G}+$ bacterial cell wall, can be recognized by TLR2, while microbial dsRNA can be recognized by TLR3.

Lipopolysaccharide (LPS) is an integral part of the G- bacterial cell wall that can be recognized by TLR4; flagellin can be recognized by TLR5 [14]. The recognition of specific MAMPs by specific TLRs mainly stimulates the production of pro-inflammatory cytokines. Once TLRs recognize a particular PAMP, they recruit adaptor proteins containing Toll/ Interleukin-1 receptor (TIR) domains that initiate downstream signaling cascades.

Eventually, the transcription factor NF- $\kappa$ B dissociates from inhibitor kappa B (I- $\kappa \mathrm{B}$ ) and translocates into the nucleus, where it controls the transcription of inflammatory mediators $[15,16]$. Moreover, different toll-like receptors have been shown to possess different functions. In the present study, our results suggest that pre-treatment of CLP-challenged mice with flagellin inhibited other TLRs, including TLR-3 and TLR-4, thereby indicating that toll-like receptors may have different functions in initiating different downstream signaling pathways. For example, TLR-5 may be closely related with the proliferation and repair of endothelial cells.

The results of our real-time PCR analysis showed that IL-1RN and VCAN were involved in the wound repair process of endothelial cells. IL-1RN has previously been proposed as a potent inhibitor of microbe-induced pro-inflammatory molecules. However, the downregulation of IL-1RN has been shown to be required for wound repair; interestingly, flagellin strongly inhibited the expression of IL-1RN. IL-1RN is an inhibitor of the pro-inflammatory cytokine IL-1 receptor. Our results showed that flagellin pretreatment inhibited the production of TNF- $\alpha$ and IL- 8 in BALF, which may be the mechanism behind the downregulation of IL-1RN. Additionally, the functions of IL- 1 and VCAN are correlated with each other. VCAN expression increased concomitant with the downregulation of IL-IRN, thereby promoting endothelial repair and decreasing septic severity.

IL-1RN and VCAN are required for appropriate cellular homeostasis and adaptation to diverse stresses. This action is particularly salient for endothelial cells in the context of wound repair processes, which are highly influenced by gradients of matrix proteins [17, 18]. The major finding in this study is that the downregulation of IL-1RN and upregulation of VCAN are very important for the wound repair of endothelial cells in acute lung injury, although decreased IL-1RN and excessive VCAN expression may enlarge the inflammatory reaction and induce various diseases $[19,20]$. Thus, this work highlights an important and distinct role for IL-1RN and VCAN in the regulation of endothelial cell phenotype and function. Flagellin was recognized by TLR-5. However, the effect of flagellin-induced TLR5 activation remains unclear. In the future, we will study the relationship between TLR- 5 activation and the subsequent downregulation of IL-1RN.

In conclusion, our results suggest that flagellin inhibits the expression of IL-1RN and promotes the expression of VCAN through the activation of TLR-5. This interaction leads to the rapid repair of endothelial cells and decreases septic severity. However, the definitive implication of toll-like receptors, IL-1RN and VCAN remains to be established. 


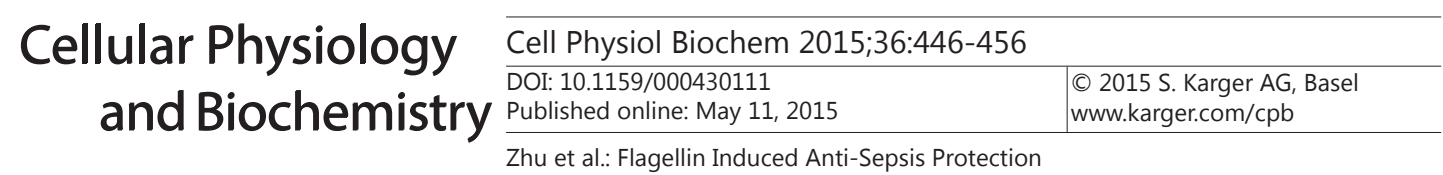

\section{Acknowledgements}

This work was supported by grants from the National Natural Science Foundation of China (No. 81171848 and No. 81301658).

\section{Disclosure Statement}

No other disclosure statement.

\section{References}

1 Boisram3-Helms J, Kremer H, Schini-Kerth V, Meziani F: Endothelial dysfunction in sepsis. Curr Vasc Pharmacol 2013;11:150-160.

2 Wu TT, Chen TL, Loon WS, Tai YT, Cherng YG, Chen RM: Lipopolysaccharide stimulates syntheses of tolllike receptor 2 and surfactant protein-A in human alveolar epithelial A549 cells through upregulating phosphorylation of MEK1 and ERK1/2 and sequential activation of NF- $\kappa$ B. Cytokine 2011;55:40-47.

3 Dinarello CA, Simon A, van der Meer JW: Treating inflammation by blocking interleukin-1 in a broad spectrum of diseases. Nat Rev Drug Discov 2012;11:633-652.

4 Petrasek J, Bala S, Csak T, Lippai D, Kodys K, Menashy V, Barrieau M, Min SY, Kurt-Jones EA, Szabo G: IL-1 receptor antagonist ameliorates inflammasome-dependent alcoholic steatohepatitis in mice. J Clin Invest 2012;122:3476-3489.

5 Bustos ML, Huleihel L, Meyer EM, Donnenberg AD, Donnenberg VS, Sciurba JD, Mroz L, McVerry BJ,Ellis BM, Kaminski N, Rojas M: Activation of human mesenchymal stem cells impacts their therapeutic abilities in lung injury by increasing interleukin (IL)-10 and IL-1RN levels. Stem Cells Transl Med 2013;2:884-895.

6 Burns TA, Dours-Zimmermann MT, Zimmermann DR, Krug EL, Comte-Walters S, Reyes L, Davis MA, Schey KL, Schwacke JH, Kern CB, Mjaatvedt CH: Imbalanced expression of Vcan mRNA splice form proteins alters heart morphology and cellular protein profiles. PLoS One 2014;9:e89133.

7 Hattori N, Carrino DA, Lauer ME, Vasanji A, Wylie JD, Nelson CM, Apte SS: Pericellular versican regulates the fibroblast-myofibroblast transition: a role for ADAMTS5 protease-mediated proteolysis. J Biol Chem. 2011;286:34298-34310.

8 Zimmermann DR, Ruoslahti E: Multiple domains of the large fibroblast proteoglycan, versican. EMBO J 1989;8:2975-2981.

9 Wight TN, Kang I, Merrilees MJ: Versican and the control of inflammation. Matrix Biol 2014;35:152-161.

10 Chang MY, Tanino Y, Vidova V, Kinsella MG, Chan CK, Johnson PY, Wight TN, Frevert CW: A rapid increase in macrophage-derived versican and hyaluronan in infectious lung disease.Matrix Biol 2014;34:1-12.

11 Skandalis SS, Kletsas D, Kyriakopoulou D, Stavropoulos M, Theocharis DA: The greatly increased amounts of accumulated versican and decorin with specific post-translational modifications may be closely associated with the malignant phenotype of pancreatic cancer. Biochim Biophys Acta 2006;1760:12171225.

12 Paul-Clark MJ, George PM, Gatheral T, Parzych K, Wright WR, Crawford D, Bailey LK, Reed DM, Mitchell JA: Pharmacology and therapeutic potential of pattern recognition receptors. Pharmacol Ther 2012;135:200215.

13 Pei J, Ding X, Fan Y, Rice-Ficht A, Ficht TA: Toll-like receptors are critical for clearance of Brucella and play different roles in development of adaptive immunity following aerosol challenge in mice. Front Cell Infect Microbiol 2012;2:115.

14 He H, Genovese KJ, Nisbet DJ, Kogut MH: Profile of Toll-like receptor expressions and induction of nitric oxide synthesis by Toll-like receptor agonists in chicken monocytes. Mol Immunol 2006;43:783-789.

15 Nguyen VP, Chen J, Petrus MN, Goldman CK, Kruhlak MJ, Bamford RN, Waldmann TA: A new domain in the Toll/IL-1R domain-containing adaptor inducing interferon- $\beta$ factor protein amino terminus is important for tumor necrosis factor- $\alpha$ receptor-associated factor 3 association, protein stabilization and interferon signaling. J Innate Immun 2014;6:377-393. 
16 Stokes JA, Cheung J, Eddinger K, Corr M, Yaksh TL: Toll-like receptor signaling adapter proteins govern spread of neuropathic pain and recovery following nerve injury in male mice.J Neuroinflammation 2013;10:148.

17 Geiser T, Atabai K, Jarreau PH, Ware LB, Pugin J, Matthay MA: Pulmonary edema fluid from patients with acute lung injury augments in vitro alveolar epithelialrepair by an IL-1beta-dependent mechanism. Am J Respir Crit Care Med 2001;163:1384-1388.

18 Toeda K, Nakamura K, Hirohata S, Hatipoglu OF, Demircan K, Yamawaki H, Ogawa H, Kusachi S, Shiratori Y, Ninomiya Y: Versican is induced in infiltrating monocytes in myocardial infarction. Mol Cell Biochem 2005;280:47-56.

19 de Luca A, Smeekens SP, Casagrande A, Iannitti R, Conway KL, Gresnigt MS, Begun J, Plantinga TS,Joosten LA, van der Meer JW, Chamilos G, Netea MG, Xavier RJ, Dinarello CA, Romani L, van de Veerdonk FL: IL-1 receptor blockade restores autophagy and reduces inflammation in chronic granulomatous disease in mice and in humans. Proc Natl Acad Sci U S A 2014;111:3526-3531.

20 Yeung TL, Leung CS, Wong KK, Samimi G, Thompson MS, Liu J, Zaid TM, Ghosh S, Birrer MJ, Mok SC: TGF- $\beta$ modulates ovarian cancer invasion by upregulating CAF-derived versican in the tumor microenvironment. Cancer Res 2013;73:5016-5028. 